indicates increased risk for microvascular disease. $N$ Engl J Med 1981;305:191-4.

4. Pal B, Anderson J, Griffiths ID, Dick WC. Rheumatic disorders in diabetes mellitus: association between limited joint mobility and Dupuytren's contracture [Abstract]. Br J Rheumatol 1986;25:122-3.

5. Prokop DJ, Tuderman L, Guzman NA. Collagen in normal and diseased connective tissue. In: McCarty JD, ed. Arthritis and allied conditions. 9th edn. Philadelphia: Lea \& Febiger, 1979.

6. Buckingham BA, Vitto J, Sandbork $\mathrm{C}$, et al. Scleroderma like syndrome and non-enzymatic glycosylation of collage in children with poorly controlled insulin dependent diabetes [Abstract]. Paediatr Res 1981:5:626.

7. Schnider SL, Kohn RR. Effects of age and diabetes on the solubility and non-enzymatic glycosylation of human skin collage. J Clin Invest $981 ; 67: 1630-5$.

8. Bollinger A, Frey J, Jager K, et al. Patterns of diffusion through skin capillaries in patients with longterm diabetes. N Engl J Med 1982;307:1305-20.

\section{Clinical and Echocardiographic Assessment in Juvenile-onset Spondyloarthropathy}

SIR-Aortic incompetence (AI) has been noted to develop in adults with ankylosing spondylitis (AS), Reiter's syndrome (RS) and other subsets of spondyloarthritis [1]. It is considered uncommon in juvenile cases and only 10 cases have been reported [2-8]. M-mode and two-dimensional echocardiography with pulsed Doppler (Echo-Doppler) were used to determine whether changes of the aortic root or valve could be identified in all the juvenileonset spondyloarthritis patients seen by our rheumatology unit over a 7 -year period. There were 20 cases (Table III) referred from within our own small region. Their present ages range from 7 to 36 (average 17) years, the age at onset of their rheumatic disease was between 3 and 16 (average 12) years and the mean duration of follow-up was 5 years. Five had obvious clinical and radiological signs of AS, five had complete or incomplete RS and none had psoriatic or intestinal arthropathy. In 10 there was a pauciarticular onset without back pain, sacroiliitis or extra-articular manifestations. HLA-B27 phenotype was found in 19.

AI was diagnosed when a typical early diastolic

TABLE III

INCIDENCE OF AORTIC INCOMPETENCE AND MITRAL VALVE Prolapse IN JUVENILE ONSET SPONDYLoARTHROPATHY

\begin{tabular}{lcccc}
\hline Diagnosis & $\begin{array}{c}\text { No. of } \\
\text { cases (B27 } \\
\text { +ve) }\end{array}$ & Males & $\begin{array}{c}\text { Aortic } \\
\text { incom- } \\
\text { petence } \\
\text { No (\%) }\end{array}$ & $\begin{array}{c}\text { Mitral } \\
\text { valve } \\
\text { prolapse } \\
\text { No (\%) }\end{array}$ \\
\hline $\begin{array}{l}\text { Ankylosing } \\
\text { spondylitis }\end{array}$ & $5(4)$ & 5 & $1(20)$ & $1(20)$ \\
$\begin{array}{l}\text { Reiter's } \\
\text { syndrome }\end{array}$ & $5(5)$ & 4 & - & $2(40)$ \\
$\begin{array}{l}\text { Pauciarticular } \\
\text { arthritis }\end{array}$ & $10(10)$ & 7 & $3(33)$ & $5(50)$ \\
\begin{tabular}{l} 
Total \\
\hline otal
\end{tabular} & $20(19)$ & 16 & $4(20)$ & $8(40)$ \\
\hline
\end{tabular}

murmur was audible along the left sternal border and/or a typical diastolic Doppler signal was demonstrated under the aortic valve on the EchoDoppler as well as a diastolic fluttering of the anterior leaflet of the mitral valve. Severity of AI was arbitrarily assessed in relation to clinical and echocardiographic data. Al was considered as mild in asymptomatic patients if auscultation and EchoDoppler revealed a typical AI in the absence of an increased left ventricular cavity. The Doppler signal of regurgitation had to be recorded in the left ventricle only below the aortic leaflets. It was considered severe when patients were symptomatic, the left ventricular cavity enlarged and AI recorded in the left ventricle beyond the tip of the mitral valve. Conventional echocardiographic criteria for mitral valve prolapse (MVP) were applied [9]. In a strictly perpendicular M-mode echocardiographic examination, a minimum $3 \mathrm{~mm}$ posterior bulging to the left atrium of the echoes of one or both mitral leaflets was requested. In the apical-view examination, a minimum $3 \mathrm{~mm}$ posterior bulging to the left atrium of one or both leaflets was requested. Attention was also paid to accessory signs such as thickness and protomesosystolic anterior motion of the mitral valve.

None of the patients had signs of cardiac failure. A faint early diastolic murmur along the upper left sternal border was reported in three cases 2 months, and 4,5 and 7 years after arthritis was diagnosed. Aortic regurgitation was confirmed by Echo-Doppler in all three cases. AI was severe in one and mild in two. In the 17 cases with normal auscultation, Echo-Doppler revealed in a 10-yearold girl, with a 7-year history of rheumatic complaints, minimal AI in a tricuspid aortic valve. Clinically silent MVP was detected in eight patients (Table III), two of them having AI. None of the cases with MVP had reduced chest expansion, vertebral syndesmophytes, pectus excavatum, severe scoliosis, straight back hypermobility or Marfan's syndrome. None had pericardial effusion or thickening. Left ventricular dimensions and performances were normal in all but one case with $\mathrm{AI}$. No atrioventricular conduction defects were observed on ECG. Anterior uveitis occurred in only one patient who had no cardiac abnormality. All cases with AI and/or MVP possessed HLA-B27 antigen.

The occurrence of AI in juvenile-onset $\mathrm{AS}$ has been known for a considerable time [3] and in adults, the incidence varies between 0.9 and $10 \%$. In conventional ECG recordings, none of our cases had the atrioventricular conduction defects which occur in adult onset AS. AI developed in one case within as little as 2 months of arthritis and in the other two after several years. Murmurs of AI have been reported to occur after 10 months [2], 1 year $[3,8]$ and 4 years $[5]$ of arthritis. AI has also been shown to antedate the onset of arthritis in an adolescent [4].

Our data are consistent with AI being a frequent 
finding in juvenile-onset spondyloarthropathy. It appears to be well tolerated and left ventricular hypertrophy was found in only one patient. However, rapid progression with aortic valve replacement has been documented [4].

The recording of eight cases ( $40 \%$ ) of MVP was unexpected. However, our diagnostic criteria of MVP may be oversensitive. If we had applied later criteria [10], MVP would have been diagnosed in none of our patients.

Six of the patients with MVP were male, which is surprising since there is a known female predominance. Two had a combination with AI. None of the acknowledged clinical associations of MVP were encountered, raising the possibility that it could be causally related to spondyloarthropathy.

The recognition of $\mathrm{AI}$ and MVP is important since these valves may be predisposed to infective endocarditis and AI may become severe enough to require valve replacement.

\section{J. C. Gerster ${ }^{1}$}

M. PAYOT ${ }^{2}$

P. PICCININ'

1Rheumatology and Rehabilitation Centre, and ${ }^{2}$ Paediatric Cardiology Department, University Hospital, Chuv, 1011-Lausanne, Switzerland.

1. Ball J. Pathology and pathogenesis. In: Moll JMH, ed. Ankylosing spondylitis. Edinburgh: Churchill Livingstone, 1980;96-112.

2. Kean WF, Anastassiades TP, Ford PM. Aortic incompetence in HLA B27 positive juvenile arthritis. Ann Rheum Dis 1980;39:294-5.

3. Bulkley BH, Roberts WC. Ankylosing spondylitis and aortic regurgitation: description of the characteristic cardiovascular lesion from study of eight necropsy patients. Circulation 1973;48:1014-27.

4. Stewart SR, Robbins DL, Castles JJ. Acute fulminant aortic and mitral insufficiency in ankylosing spondylitis. N Engl J Med 1978;229:1448-9.

5. Reid GD, Patterson MWH, Patterson AC, et al. Aortic insufficiency in association with juvenile ankylosing spondylitis. I Pediatr 1979;95:78-80.

6. Ansell BM. Juvenile spondylitis and related disorders. In: Moll JMH, ed. Ankylosing spondylitis. Edinburgh: Churchill Livingstone, 1980;120-36.

7. Rosenberg AM, Petty RE. A syndrome of seronegative enthesopathy and arthropathy in children. Arthritis Rheum 1982;25:1041-7.

8. Pelkonen P, Byring R, Pesonen E, et al. Rapidly progressive aortic incompetence in juvenile ankylosing spondylits: a case report. Arthritis Rheum 1984; 27:698-700.

9. Markiewicz W, Stoner J, London E, et al. Mitral valve prolapse in one hundred presumably healthy young females. Circulation 1976;53:464-73.

10. Warth DC, King ME, Cohen JM, Tesoriero VL, Marcus $E$, Weyman AE. Prevalence of mitral valve prolapse in normal children. $J$ Am Coll Cardiol 1985;5: 1173-7.

\section{Reiter's Syndrome and Amyloidosis}

SIR-Reiter's syndrome (RS) is a well-characterized symptom complex consisting of urethritis, conjunctivitis, mucocutaneous lesions and arthritis. It generally runs a protracted clinical course with exacerbations and remissions but less frequently patients develop a chronic severely debilitating illness. There is considerable clinical overlap between RS and ankylosing spondylitis (AS) and both are strongly associated with the HLA-B27 antigen $[1,2]$. However, whereas up to $10 \%$ of AS individuals may develop amyloidosis [3], it is rarely seen in RS and only three cases have been reported [4-6]. This is surprising in view of the similarities between the two conditions and the prolonged severe inflammation often observed in RS. We report here the case of a man with a severe, chronic, multisystem disease who developed amyloidosis and the nephrotic syndrome 14 years after the onset of RS.

A 32-year-old Australian white male was admitted for investigation of nephrotic syndrome. He was well until 14 years earlier when, after an episode of urethritis, thought to be gonorrhoea, he was treated with penicillin. Four weeks later he developed arthritis in the proximal interphalangeal joint of an index finger, both ankles, right knee, left elbow and bilateral plantar fasciitis. A diagnosis of RS was made and he was commenced on phenylbutazone $100 \mathrm{mg}$ b.d. Two years later he suffered a severe episode of anterior uveitis which failed to respond to topical and systemic steroid therapy and one eye was eventually enucleated.

Over the next two years, the patient had persistent disease activity, which was poorly responsive to nonsteroidal anti-inflammatory agents and required systemic corticosteroid therapy (betamethasone $0.5 \mathrm{mg}$ b.d.). This failed to give adequate disease control and he developed prominent signs of Cushing's syndrome including hypertension (BP 160/110). Azathioprine was commenced ( $200 \mathrm{mg}$ mane) and corticosteroids were reduced (prednisolone $5 \mathrm{mg} /$ day). Synovectomies of both knees were performed followed by bilateral hip replacement and arthroplasty of one knee 10 and 13 years after disease onset. The patient was severely incapacitated by his chronic polyarthritis.

There was a family history of arthritis which affected the patient's father and older brother, but no history of iritis or amyloidosis. On admission he was wasted with cushingoid facies and there was prominent synovitis involving shoulders, elbows, wrists, all metacarpophalangeal joints, knees, ankles and feet. Marked spinal kyphosis and loss of lumbar lordosis were evident. There was a hyperkeratotic, scaly rash over the ankles and calves but no evidence of psoriasis. Abdominal examination revealed hepatomegaly and $3 \mathrm{~cm}$ of non-tender splenomegaly but the kidneys were not palpable. He was mildly hypertensive with ankle oedema but no other features of heart failure were present. Fundoscopy revealed grade II hypertensive retinopathy. His $\mathrm{Hb}$ was $12.2 \mathrm{~g} / \mathrm{dl}$, WBC $8.1 \times 10^{\circ} /$, 